\title{
Classic serotonergic psychedelics for mood and depressive symptoms: a meta-analysis of mood disorder patients and healthy participants
}

\author{
Nicole L. Galvão-Coelho ${ }^{1,2,3,4,5}$ (D) Wolfgang Marx ${ }^{6} \cdot$ Maria Gonzalez $^{4} \cdot$ Justin Sinclair ${ }^{4} \cdot$ Michael de Manincor $^{4} \cdot$ \\ Daniel Perkins ${ }^{7} \cdot$ Jerome Sarris ${ }^{4,8}$
}

Received: 5 August 2020 / Accepted: 13 November 2020 / Published online: 11 January 2021

(C) The Author(s) 2021

\begin{abstract}
Rationale Major depressive disorder is one of the leading global causes of disability, for which the classic serotonergic psychedelics have recently reemerged as a potential therapeutic treatment option.

Objective We present the first meta-analytic review evaluating the clinical effects of classic serotonergic psychedelics vs placebo for mood state and symptoms of depression in both healthy and clinical populations (separately).

Results Our search revealed 12 eligible studies ( $n=257 ; 124$ healthy participants, and 133 patients with mood disorders), with data from randomized controlled trials involving psilocybin $(n=8)$, lysergic acid diethylamide ([LSD]; $n=3)$, and ayahuasca $(n=1)$. The meta-analyses of acute mood outcomes ( $3 \mathrm{~h}$ to 1 day after treatment) for healthy volunteers and patients revealed improvements with moderate significant effect sizes in favor of psychedelics, as well as for the longer-term (16 to 60 days after treatments) mood state of patients. For patients with mood disorder, significant effect sizes were detected on the acute, medium (2-7 days after treatment), and longer-term outcomes favoring psychedelics on the reduction of depressive symptoms.

Conclusion Despite the concerns over unblinding and expectancy, the strength of the effect sizes, fast onset, and enduring therapeutic effects of these psychotherapeutic agents encourage further double-blind, placebo-controlled clinical trials assessing them for management of negative mood and depressive symptoms.
\end{abstract}

Keywords Depression · Psilocybin · Ayahuasca $\cdot$ LSD $\cdot$ Mescaline $\cdot$ Placebo

\section{Introduction}

\section{Overview}

There is currently a resurgence of research investigating the use of psychedelic substances in the treatment of mood disorders, mainly the "classic serotonergic psychedelics" (Chi and

Nicole L. Galvão-Coelho

nicolelgalvaocoelho@gmail.com

1 Laboratory of Hormone Measurement, Department of Physiology and Behavior, Federal University of Rio Grande do Norte, Natal, RN, Brazil

2 Postgraduate Program in Psychobiology and Department of Physiology and Behavior, Federal University of Rio Grande do Norte, Natal, RN, Brazil

3 National Institute of Science and Technology in Translational Medicine, São Paulo, Brazil
Gold 2020; Dos Santos et al. 2018; Reiff et al. 2020; Schenberg 2018). This class of psychedelics includes psilocybin, dimethyltryptamine ([DMT], often consumed via the traditional plant preparation ayahuasca), lysergic acid diethylamide (LSD), and mescaline. These substances may induce psychedelics effects as potential agonists of the serotonin $2 \mathrm{~A}$ receptors. Although it is recognized, they may also

4 NICM Health Research Institute, Western Sydney University, Westmead, Australia

5 Departamento de Fisiologia e Comportamento, Universidade Federal do Rio Grande do Norte, Caixa Postal, 1511, CEP: 59078-970 Natal, RN, Brasil

6 IMPACT Research Institute, School of Medicine, Deakin University, Geelong, Australia

7 School of Social and Political Science, University of Melbourne, Melbourne, Australia

8 Professorial Unit, The Melbourne Clinic, Department of Psychiatry, University of Melbourne, Melbourne, Australia 
interact to a lesser extent with other neurotransmitter pathways, such as partial agonism of the serotonin $2 \mathrm{C}$ receptors, through which they may also induce antidepressant activity (Araujo et al. 2015; Baumeister et al. 2014; Halberstadt and Geyer 2011).

One factor contributing to this resurgence is the limited success of existing pharmacotherapies for patients with depressive disorders (Thase et al. 2001). Many antidepressants may have a long latency to therapeutic response, requiring two to 6 weeks to produce effects, and can potentially induce undesirable side-effects, resulting in increased patient distress or discontinuation of treatment (Blier and de Montigny 1994; Carvalho et al. 2016; Posternak and Zimmerman 2005). A substantial portion of depressed patients do not benefit substantially from antidepressant treatment, (Cipriani et al. 2018; Hengartner and Plöderl 2018; Kirsch 2014; Munkholm et al. 2019; Thase et al. 2001). As a result, up to half of patients with depression may develop treatment-resistant disorders, defined as a failure to achieve remission with two or more adequate antidepressant trials (Akil et al. 2018; Conway et al. 2017).

Given the scale and impact of this problem, innovative treatment approaches for major depression are urgently needed, and it is in this context that there has been renewed clinical and research interest in the classic serotonergic psychedelics (Dos Santos et al. 2018; Schenberg 2018). In general, serotonergic psychedelics do not lead to withdrawal or compulsive drug-seeking behaviors, as are observed with substances such as opioids and cocaine (Bogenschutz and Johnson 2016; McKenna 2004). They are generally considered safe and do not induce physiological toxicity or lasting adverse effects, although transitory signs of cognitive and emotional alterations, and mild sympathetic activity, are common (Bogenschutz and Ross 2018). Studies examining data from the National Survey on Drug Use and Health (2001-2004) in the USA have reported no significant associations between lifetime psychedelic use and adverse mental health outcomes, including psychosis, with some evidence of reduced risk of these outcomes (Johansen and Krebs 2015; Krebs and Johansen 2013). However, restrictions on the use of psychedelics are indicated for individuals with severe cardiac disease and either a personal or family history of psychosis.

Therefore, the classic psychedelics are again being utilized in pre-clinical, observational, open-label, and randomized controlled trials examining effects on mood in psychiatry patients and healthy volunteers, with highly encouraging initial results being reported (Carhart-Harris et al. 2016b; Dolder et al. 2016; Dos Santos et al. 2011; Hasler et al. 2004; Kometer et al. 2012; Kraehenmann et al. 2015; Osorio Fde et al. 2015; PalhanoFontes et al. 2019; Ross et al. 2016; Schmid et al. 2015; Schmid and Liechti 2018; Wittmann et al. 2007). Mescaline, usually derived from the peyote cactus (Bogenschutz and Ross 2018; Heffter 1898), and LSD were investigated in older psychiatric studies, conducted to explore effects on psychosis and alcoholism (Berlin et al. 1955; Blum et al. 1977; Fuentes et al. 2019; Gouzoulis-Mayfrank et al. 1998; Hofmann 1979; Krebs and Johansen 2012; Pahnke et al. 1970; Rucker et al. 2018). More recently, LSD studies have turned to the investigation of its effect on mood (Carhart-Harris et al. 2016b; Dolder et al. 2016; Gasser et al. 2014; Gasser et al. 2015; Schmid et al. 2015; Schmid and Liechti 2018).

The current second wave of psychedelic research has primarily involved psilocybin, the main psychedelic compound of Psilocybe spp. fungi (Rucker et al. 2018). Open-label trials have been conducted in obsessive-compulsive disorder (Ballenger 2008; Moreno et al. 2006), addiction (Bogenschutz et al. 2015; Johnson et al. 2014), and treatment-resistant depression (Carhart-Harris et al. 2016a; Carhart-Harris et al. 2017), whereas double-blind trials have been conducted in patients with life-threatening cancer diagnoses (commonly exploring effects on mood and existential anxiety) (Griffiths et al. 2016; Griffiths et al. 2006; Grob et al. 2011; Hasler et al. 2004; Kometer et al. 2012; Kraehenmann et al. 2015; Ross et al. 2016; Wittmann et al. 2007). On the strength of this evidence, the United States Food and Drug Administration granted "breakthrough therapy" status to psilocybin in 2019, concluding that initial data indicate that it may provide a substantial improvement over existing treatments for treatment-resistant depression (Pathways 2018).

Ayahuasca is an Amazonian brew made with Psychotria viridis, a rubacea containing N, N-DMT, and Banisteriopsis caapi, a vine which contains $\beta$-carbolines that are reversible inhibitors of monoamine oxidase and an inhibitor of serotonin reuptake (Palhano-Fontes et al. 2014). This psychedelic also has been subject to increasing research, which has included effects on mood and addiction in healthy volunteers (McKenna 2004; Riba et al. 2001; Santos et al. 2007; Uthaug et al. 2018), as well as clinical trials investigating its psychological and neurobiological antidepressant effects in open-label and double-blind designs (de Almeida et al. 2019; Dos Santos et al. 2011; Galvão et al. 2018; Osorio Fde et al. 2015; PalhanoFontes et al. 2019; Zeifman et al. 2019).

\section{Aims and objective}

As a consequence of the expanding number of clinical studies investigating psychedelic treatments for psychiatric disorders, the number of reviews on this topic has also increased in recent years (Bogenschutz and Ross 2018; Chi and Gold 2020; Dos Santos et al. 2018; Johnson et al. 2019; Muttoni et al. 2019; Ross 2018; Rucker et al. 2018). A recent metaanalysis review showed that psychedelic-assisted therapy, which included both the classic serotonergic psychedelics and MDMA (3,4-methylenedioxymethamphetamine), significantly outperformed placebo, with large effect sizes across a range of mental disorders such as unipolar depression, anxiety, and post-traumatic stress disorder (Luoma et al. 2020). 
However, to date, no meta-analysis of double-blind randomized controlled trials (RCTs) comparing the clinical efficacy of classic serotonergic psychedelics with placebo, for mood and depressive symptoms, has been published. Our aim is to present the first meta-analysis in this area, by evaluating the clinical effect of classic serotonergic psychedelics on negative mood state and depressive symptoms, in double-blind RCTs, separately for both healthy volunteers and patients diagnosed with a mood disorder.

\section{Methods}

The search strategy and data synthesis were conducted in line with the Preferred Reporting Items for Systematic Reviews and Meta-Analyses (PRISMA) statement (Moher et al. 2009) and followed a registered protocol (PROSPERO registration number: CRD42020158356).

\section{Systematic search}

The systematic search was conducted using the Cochrane Central Register of Controlled Trials, Cochrane Database of Systematic Reviews, Health Technology Assessment Database, Allied and Complementary Medicine, PsycINFO, and Ovid MEDLINE(R), from journal inception to May, 2020. A search via Web of Science was conducted using the same keywords to identify any additional relevant articles. Reference lists of included articles were also searched. During the initial screening, 4 raters (NLGC, MG, JS, and $\mathrm{MM}$ ) independently assessed articles retrieved for eligibility based on the title, abstract, and in method, after which full text articles were retrieved and screened.

\section{Eligibility criteria}

Eligibility criteria were organized in accordance with the PICO (participants, interventions, comparisons, and outcomes) reporting structure, as described below. The search terms used in systematic review search are summarized in Table 1.

\section{Participants}

After a systematic search of the relevant data, we included studies with both healthy individuals and patients with mood disorders who were diagnosed using the Diagnostic and Statistical Manual of Mental Disorders IV (DSM-IV) (Table 1). The data for patients with a mood disorder and healthy participants were analyzed separately to avoid conflating heterogeneous populations.
Table 1 Search terms used in systematic review search

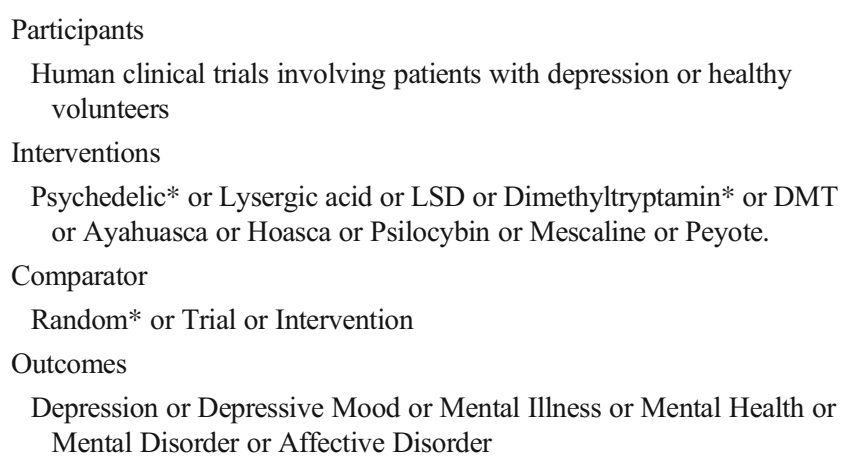

\section{Interventions}

All classic serotonergic psychedelic interventions were included: mescaline, LSD, DMT/Ayahuasca, and psilocybin. However, after a systematic search, we included studies that investigated psychedelic interventions using the "psychedelic model," where interventions were provided to participants in moderate to high doses in single or multiple sessions (Reiff et al. 2020; Ross 2012). Studies using micro-doses and low doses of psychedelics (e.g., for psilocybin below $100 \mu \mathrm{g} / \mathrm{kg}$ ) (Hasler et al. 2004) were excluded.

\section{Comparation}

All studies included were randomized, placebo-controlled, and double-blind trials, which had either a cross-over or parallel design, with outcomes between $3 \mathrm{~h}$ and 60 days after dosing session (see below the "Outcomes" section for more details). Control groups must have been an inactive comparator such as a placebo, low-dose psychedelic, or a nonpsychoactive pharmacological agent (e.g., niacin).

\section{Outcomes}

We included trials that used clinically validated scales for depression or mood state outcomes. For depression symptoms, those scales were as follows: Hamilton Depression Rating Scale (HAM-D), Montgomery-Åsberg Depression Rating Scale (MADRS), Beck Depression Inventory (BDI), and Hospital Anxiety and Depression Scale (HADS; specifically, the depressive sub-score). To measure mood state, the following scales were included: Adjective Mood Rating Scale (AMRS; specifically anxiety-depressiveness subscore), Positive and Negative Affect Schedule (PANAS; specifically negative score), Profile of Mood States (POMS), and Persisting Effects Questionnaire (PEQ; specifically negative mood). 
To provide temporal clarity of the psychedelic's effects (Carhart-Harris et al. 2016b), the outcomes of mood state and depressive symptoms were categorized and analyzed with respect to time-point collected after the respective dosing session:

- Acute effects: outcomes from $3 \mathrm{~h}$ to 1 day after dosing session.

- Medium-term effects: outcomes from 2 to 15 days after dosing session.

- Long-term effects: outcomes from 16 to 60 days after dosing session.

These time-points were selected because antidepressant drugs commonly require approximately 2 weeks to initiate a therapeutic response (Cipriani et al. 2018; Hengartner and Plöderl 2018), while the psychotropic effects of substances with psychedelic actions, for instance ketamine and classical serotonergic psychedelics, commence within hours and have been reported to last approximately 2 weeks (Corriger and Pickering 2019; Sanacora et al. 2017).

We excluded data from studies with outcomes measured within less than $3 \mathrm{~h}$ of receiving the psychedelic to avoid assessment confounding from changes in cognition and perception induced acutely by the substance. Furthermore, data was also excluded from trials with data collected 60 days or longer after the intervention due to the poor reliability of retrospective data. Outcomes from the open-label phase of double-blind studies were also not included. There was no restriction based on sample size, the duration or severity of symptoms, comorbid disorders, or participant demographics.

\section{Quality assessment of included clinical trials}

The quality of eligible clinical trials was assessed using the Jadad scale (Jadad et al. 1996) completed by author NLGC and cross-checked by WM and JS.

\section{Data extraction and analysis}

Effect size data of each experimental group was extracted and converted to standardized mean differences (SMD) with 95\% confidence intervals (CIs). Data were initially extracted by one author (NLGC), and then cross-checked independently by an additional author (WM). In line with conventional interpretations, SMD were classified as negligible $(<0.2)$, small $(0.2-0.4)$, moderate $(0.4-0.8)$, or large $(>0.8)$ (Higgins and Green 2011).

In cases where continuous outcomes were reported as weighted mean differences or raw mean differences, these were recalculated into an SMD (Hedges'g) using Comprehensive Meta-Analysis 3.0. Studies that reported the outcomes by the following: (a) psychedelics dose (Hasler et al.
2004; Wittmann et al. 2007) and (b) separately for sessions before and after cross-over (Griffiths et al. 2016; Griffiths et al. 2006; Ross et al. 2016), each outcome having their data combined and the mean of the SMD being used in analysis. When there was more than one outcome, the effect sizes were calculated for each one and then the averaged was used in the meta-analysis (Higgins and Green 2011).

We also extracted the number of participants $(N)$, along with the number of trials/comparisons $(K)$ from which the pooled effect size was derived. Additionally, all analyses were performed with a random-effect model, which considers both between-study and within-study variability. The heterogeneity was quantified using the $I^{2}$ statistic, and categorized as low $\left(I^{2}<25 \%\right)$, moderate $\left(I^{2}=25-50 \%\right)$, or high $\left(I^{2}>50 \%\right)$. Other relevant study characteristics were also extracted, specifically with regard to dose and if psychotherapy support was offered.

Sub-group or secondary analyses of clinical response with respect to the type of psychedelic substance or population (patients with a mood disorder or healthy volunteers) were also undertaken. Safety and tolerability outcomes were not included in the meta-analysis due to marked heterogeneity in reporting. Instead, this information was extracted and narratively reviewed. Although there is a recognized difficulty in having appropriate blinding in studies with psychedelics, we assumed for the calculation of the JADAD score that an appropriate placebo could include substances that may induce some similar physiological and/or cognitive effect of psychedelics, such as methylphenidate, niacin, or low doses of the psychedelics. The potential impact of publication bias was assessed using fail-safe $\mathrm{N}$ and Egger's regression test of the intercept. A statistically significant effect was regarded as a $p$ value of $<0.05$. The data was analyzed and figures prepared via Comprehensive Meta-Analysis 3.0.

\section{Results}

\section{Systematic search results}

The search returned 570 results, which was reduced to 565 after duplicates were removed. Title and abstract screening removed 533 articles, while 32 manuscripts were retrieved and reviewed in full. Of these, 14 were open-label clinical trials and consequently were not included in this metaanalysis (Bogenschutz et al. 2015; Carhart-Harris et al. 2018; Carhart-Harris et al. 2016a; Carhart-Harris et al. 2017; Carhart-Harris et al. 2011; Kaelen et al. 2018; Lyons and Carhart-Harris 2018a; Lyons and Carhart-Harris 2018b; Osorio Fde et al. 2015; Roseman et al. 2017; Sanches et al. 2016; Stroud et al. 2018). From the 18 double-blind trials selected, 6 were excluded because they did not meet the inclusion criteria. Specifically, 3 did not have a placebo-control design (Daumann et al. 2008; Gouzoulis-Mayfrank et al. 
2005; Schmid and Liechti 2018); 1 clinical trial used microdoses of LSD (Bershad et al. 2019); 1 trial measured outcomes only $2 \mathrm{~h}$ after treatment (Santos et al. 2007), and one clinical trial showed unpublished outcomes collected after 60 days of psychedelic dosing session (Griffiths et al. 2008). Thus, we were left 12 studies which met the criteria for inclusion. For the PRISMA flow diagram, see Fig. 1.

\section{Description of studies}

For study attributes involving type of participants, mood diagnosis, number of treatment session, psychedelic doses, and placebo type, see Table 2. Of the 12 studies included, 8 used psilocybin (Griffiths et al. 2016; Griffiths et al. 2006; Grob et al. 2011; Hasler et al. 2004; Kometer et al. 2012; Kraehenmann et al. 2015; Ross et al. 2016; Wittmann et al. 2007), 3 used LSD (Dolder et al. 2016; Gasser et al. 2014; Schmid et al. 2015), and 1 used DMT in the form of ayahuasca (Palhano-Fontes et al. 2019). In summary, these involved 257 participants, made up of 124 healthy volunteers and 133 patients with mood disorders. All trials provided a single psychedelic administration by dose, with exception of Gasser et al. (2014), where LSD was administered twice.
All studies utilized a cross-over design, other than PalhanoFontes et al. (2019), which used a parallel design. Ross et al. (2016), Gasser et al. (2014), Griffiths et al. (2006), and Griffiths et al. (2016) also included psychotherapy to support the psychedelic intervention. No clinical trials involving mescaline met the criteria for inclusion.

\section{Quality assessment of the included meta-analyses}

For methodological quality scores of all the clinical trials included, see supplementary material Table S1. Two studies had a maximum score of 5/5: Ross et al. (2016) (psilocybin) and Palhano-Fontes et al. 2019 (ayahuasca). Of note, from 12 studies, only 2 trials described the randomization technique used while only 7 detailed participant withdrawal. The main issue related to studies quality was the blinding process. From 12 studies included, 3 did not present details regarding the placebo condition used. However, for two of them, we were able to obtain further information directly from the study authors (Table S1).

Few studies analyzed the integrity of the blinding process by questionnaires assessed in volunteers and/or via the research team (Gasser et al. 2014; Griffiths et al. 2006;
Fig. 1 PRISMA flow diagram of systematic review and metaanalysis of classic serotonergic psychedelics for mood and depressive symptoms

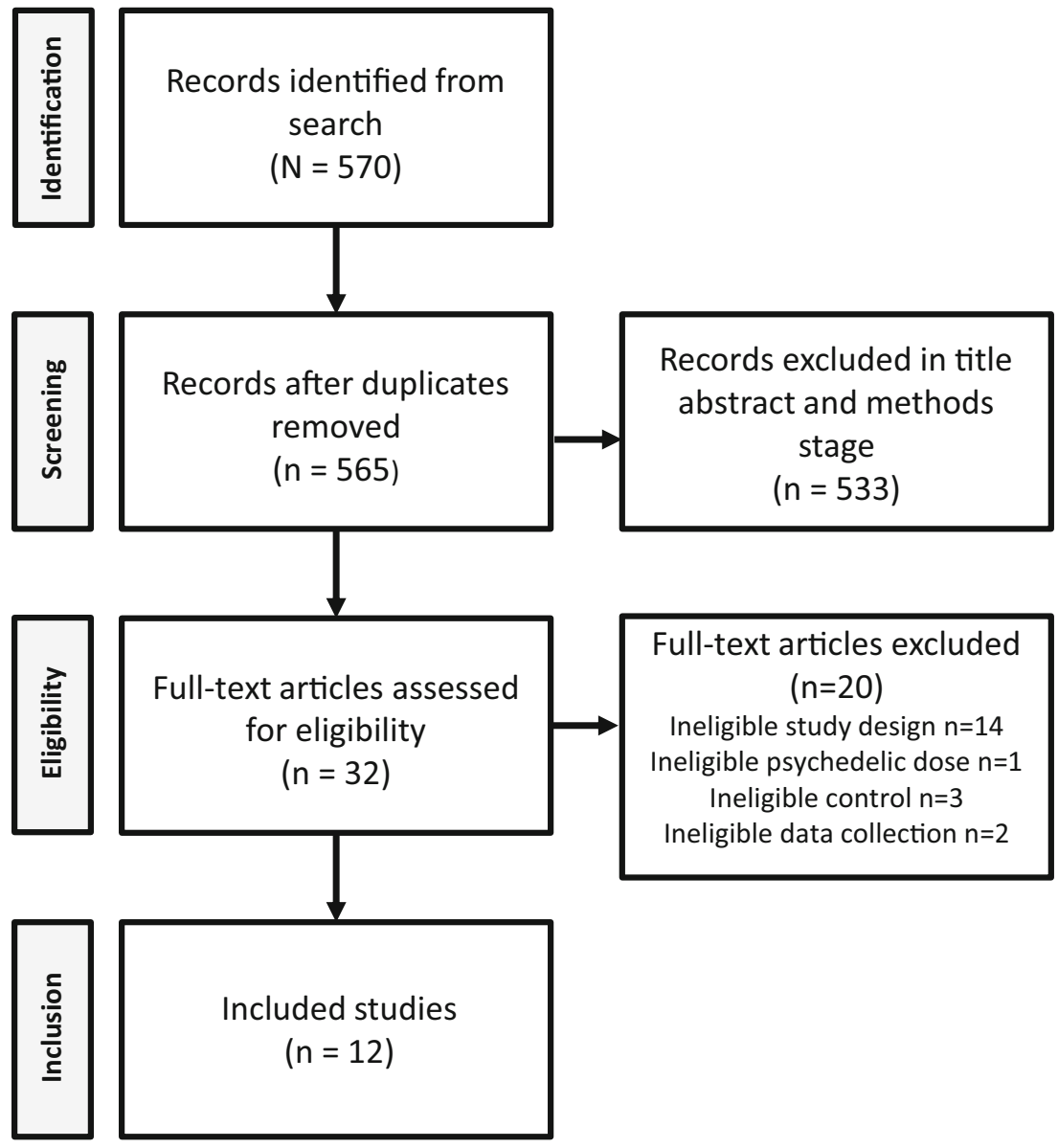


Table 2 Study summary of clinical trials included in the meta-analysis

\begin{tabular}{|c|c|c|c|c|c|c|c|}
\hline Study & Design & $N$ & Subject & Psychedelic & Dose & Session ${ }^{\#}$ & Placebo \\
\hline Gasser et al. 2014 & $\mathrm{CO}$ & 12 & $\mathrm{~A}$ and $\mathrm{LT}$ & LSD & $200 \mu \mathrm{g}$ & 2 & LSD $20 \mu \mathrm{g}$ \\
\hline Schmid et al. 2015 & $\mathrm{CO}$ & 16 & Healthy & LSD & $200 \mu \mathrm{g}$ & 1 & Mannitol** \\
\hline Dolder et al. 2016 & $\mathrm{CO}$ & 16 & Healthy & LSD & $100 \mu \mathrm{g}$ & 1 & Mannitol** \\
\hline Palhano-Fontes et al. 2019 & $\mathrm{P}$ & 29 & TRD & Ayahuasca & $360 \mu \mathrm{g} / \mathrm{kg}$ & 1 & Zinc sulfate \\
\hline Hasler et al. 2004 & $\mathrm{CO}$ & 8 & Healthy & Psilocybin & ${ }^{\&} 115,215$ and $315 \mu \mathrm{g} / \mathrm{k}$ & 4 & Lactose \\
\hline Wittmann et al. 2007 & $\mathrm{CO}$ & 12 & Healthy & Psilocybin & 115 and $250 \mu \mathrm{g} / \mathrm{kg}$ & 2 & Lactose \\
\hline Griffiths et al. 2006 & $\mathrm{CO}$ & 30 & Healthy & Psilocybin & $429 \mu \mathrm{g} / \mathrm{kg}$ & 1 & Methylphenidate \\
\hline Kometer et al. 2012 & $\mathrm{CO}$ & 17 & Healthy & Psilocybin & $215 \mu \mathrm{g} / \mathrm{kg}$ & 1 & Not specified \\
\hline Kraehenmann et al. 2015 & $\mathrm{CO}$ & 25 & Healthy & Psilocybin & $160 \mu \mathrm{g} / \mathrm{kg}$ & 1 & Lactose \\
\hline Griffiths et al. 2016 & $\mathrm{CO}$ & 51 & A, D and LT & Psilocybin & 314 and $429 \mu \mathrm{g} / \mathrm{kg}$ & 1 & $\mathrm{P}^{*} 43$ and $14 \mu \mathrm{g} / \mathrm{kg}$ \\
\hline Ross et al. 2016 & $\mathrm{CO}$ & 29 & $\mathrm{~A}$ and $\mathrm{LT}$ & Psilocybin & $300 \mu \mathrm{g} / \mathrm{kg}$ & 1 & Niacin \\
\hline Grob et al. 2011 & $\mathrm{CO}$ & 12 & $\mathrm{~A}$ and $\mathrm{LT}$ & Psilocybin & $200 \mu \mathrm{g} / \mathrm{kg}$ & 1 & Niacin \\
\hline
\end{tabular}

$C O$, cross-over; $P$, parallel; $N$, sample size; $A$, anxiety; $D$, depression; $T R D$, treatment-resistant depression; $L T$, life-threatening illness; $L S D$, lysergic acid diethylamide, $P^{*}$, psilocybin

\# Number of psychedelic sessions during the trial

${ }^{\&}$ Low dose of $45 \mathrm{mg} / \mathrm{kg}$ of psilocybin was not included in the meta-analysis

** Information provided by the author, it does not have in the manuscript

Griffiths et al. 2016; Palhano-Fontes et al. 2019; Ross et al. 2016). Griffiths et al. (2006 and 2016), while Palhano-Fontes et al. (2019) related success in the blinding process, whereas Gasser et al. (2014) and Ross et al. (2016) did not appear to achieve success in blindness despite the use as placebo a low dose of psychedelic (LSD) and niacin, respectively.

Although the participant expectancy about the study is not part of the JADAD scale, it is relevant to analyze as it can play a significant role both in blinding and in participants and evaluators responses. From 12 studies, 3 detailed some strategies aiming to reduce these expectancies, such as the use of instructional sets, multiples evaluators, naïve volunteers, individual, and not groups experiments, parallel study designer (Griffiths et al. 2006; Griffiths et al. 2016; Palhano-Fontes et al. 2019). However, no studies used expectancy measures as a cofactor in statistical analysis of clinical response.

\section{Mood state and depressive symptom outcomes}

\section{Mood state}

Meta-analyses were conducted on the measures of negative mood state of healthy volunteers and also in patients with a mood disorder, separately. Only one study was included in the systematic review, analyzing medium-term mood changes; therefore, it was not possible to undertake a meta-analysis for this time-point (Grob et al. 2011).

Meta-analysis of acute measures of mood state, collected between $3 \mathrm{~h}$ and 1 day after treatment, showed a moderate clinical effect size of psychedelics in the reduction of negative mood when compared to placebo in both healthy participants $(N=103, K=6, \mathrm{SMD}=-0.705$, CIs -0.987 to -0.424 , $\left.p<0.01 ; I^{2}=2.1 \%\right)$ and patients with a mood disorder $(N=$ $41, K=2, \mathrm{SMD}=-0.632$, CIs -1.171 to $-0.092, p=0.022$; $I^{2}=7.6 \%$ ), with low variance across studies (Healthy volunteers: Dolder et al. 2016; Hasler et al. 2004; Kometer et al. 2012; Kraehenmann et al. 2015; Schmid et al. 2015; Wittmann et al. 2007, patients: Grob et al. 2011; Ross et al. 2016) (Fig. 2 and supplementary material table S2). No study was located providing data on acute mood state changes after ayahuasca treatment.

Sub-analysis by psychedelic drug in healthy volunteers revealed a highly significant effect with a moderate effect size for both $\operatorname{LSD}(N=32, K=2, \mathrm{SMD}=-0.757$, CIs -1.203 to $-0.311, p=0.001 ; I^{2}=5.2 \%$ ) (Dolder et al. 2016; Schmid et al. 2015) and psilocybin in negative mood reduction with low variability across studies $(N=62, K=4, \mathrm{SMD}=-0.671$, CIs -1.034 to $-0.309, p<0.001 ; I^{2}=3.4 \%$ ) (Hasler et al. 2004; Kometer et al. 2012; Kraehenmann et al. 2015; Wittmann et al. 2007) (Fig. 2 and table S2).

Moreover, the meta-analysis of long-term measures of mood state, between 16 and 60 days after treatment, showed that psilocybin also had a moderate long-term effects in reduction of negative mood in patients with a mood disorder, with low heterogeneity across trials $(N=110, K=3, \mathrm{SMD}=-$ 0.495 , CIs -0.829 to $-0.161, p=0.004 ; I^{2}=2.9 \%$ ) (Griffiths et al. 2006; Ross et al. 2016) (Table S2). No studies examined long-term changes on mood state in healthy participants, and after LSD or ayahuasca treatment. 
Acute Effects of Psychedelics for Negative Mood State

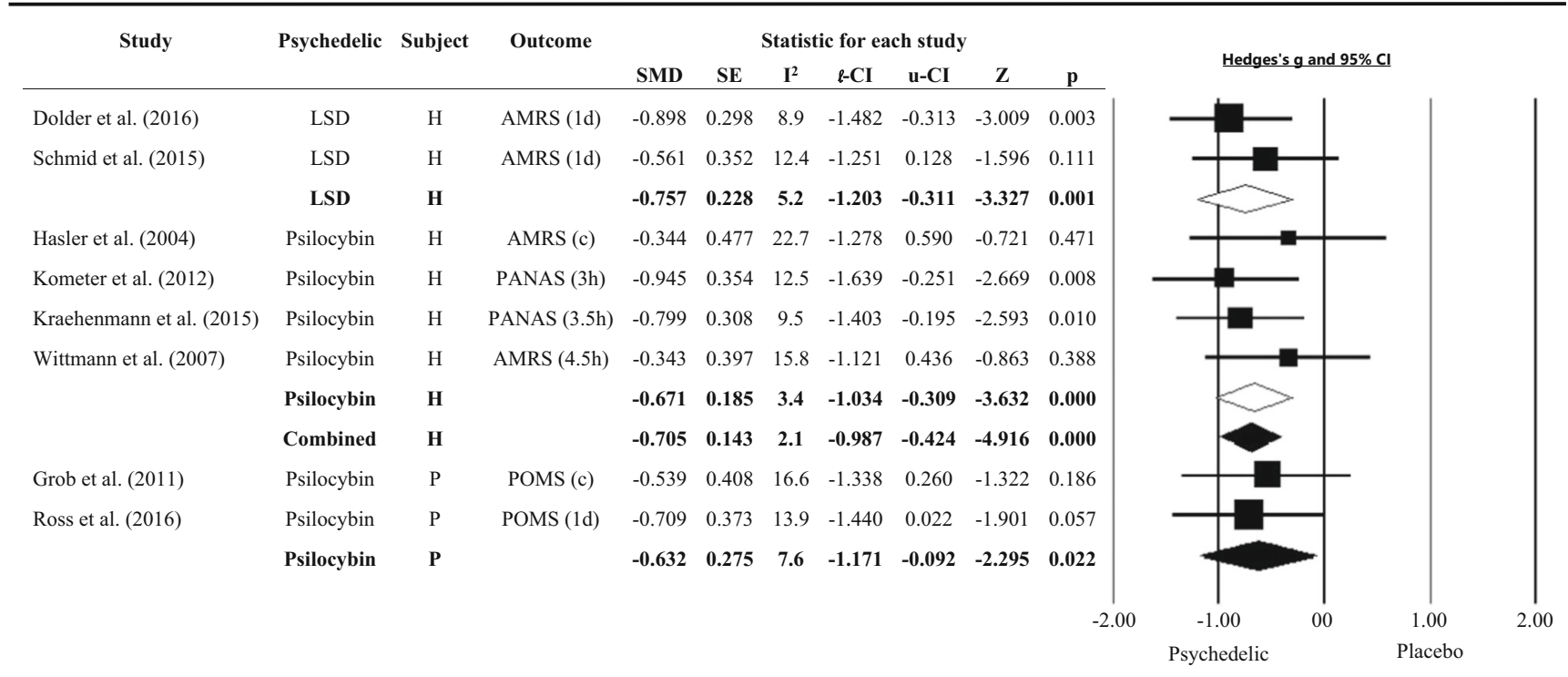

Fig. 2 The effect size (SMD) of acute clinical effects of classic serotonergic psychedelic and placebo treatments on negative mood state in healthy volunteers and patients with mood disorders, shown as Hedges' $\mathrm{g}$ with $95 \%$ confidence interval. Negative Hedges' $g$ indicates favor of psychedelics. Squares represent study effect sizes; open diamonds represent effect sizes of sub-group analyses by drug (lysergic acid diethylamide [LSD] or psilocybin); closed diamonds represent overall effect sizes for healthy volunteers $(\mathrm{H})$ or mood disorder patients $(\mathrm{P})$.

\section{Depressive symptoms}

Three meta-analyses were conducted with measures of depressive symptoms assessed by depression symptom rating scales from patients with a mood disorder: acute effects, medium-term, and longer-term clinical effects.

The meta-analysis of acute effects (between $3 \mathrm{~h}$ and 1 day) on depressive symptoms showed a significant and moderate clinical effect size of psychedelics (psilocybin and ayahuasca) for reduction of depressive symptoms. Again, low heterogeneity was observed across studies $(N=70, K=3, \mathrm{SMD}=-0.720$, CIs -1.189 to $-0.251, p=0.003 ; I^{2}=5.7 \%$ ) (Grob et al. 2011; Palhano-Fontes et al. 2019; Ross et al. 2016) (Fig. 3 and table S2). A sub-analysis of the individual psychedelics revealed that psilocybin had a significant and moderate clinical effect size on the reduction of depressive symptoms in patients with a mood disorder, with low variance across studies $(N=41$, $K=2, \mathrm{SMD}=-0.665$, CIs -1.262 to $-0.048, p=0.034 ; I^{2}=$ 9.6\%) (Grob et al. 2011; Ross et al. 2016) (Fig. 3 and table S2). There were no clinical trials located involving the acute assessment of LSD's effects on depressive symptoms.

We found a significant and large effect of classic psychedelics (psilocybin and ayahuasca) in the medium-term assessment of depressive symptoms, with low heterogeneity across studies $(N=70, K=3, \mathrm{SMD}=-0.841$, CIs -1.359 to $0.323, p=0.001 ; I^{2}=7.0 \%$ ) (Grob et al. 2011; Palhano-
The sizes of squares and diamonds are proportional to the SMD. Combined: polled LSD and psilocybin. d: day and h: hours. (c) The following instruments were grouped and the mean of SMD was used in analysis: Grob et al. (2011), Profile of Mood States (POMS) of $6 \mathrm{~h}$ and 1 day. Hasler et al. (2004), Adjective Mood Rating Scale (AMRS) of $4.5 \mathrm{~h}$ and 1 day. PANAS: Positive and Negative Affect. SE, standard error; 1-IC, low confidence interval; u-CI, up confidence interval; $I^{2}$, heterogeneity across studies (\%); $\mathrm{Z}, z$ value; $\mathrm{p}, p$ value

Fontes et al. 2019; Ross et al. 2016) (Fig. 3 and table S2). However, a secondary analysis of psilocybin studies showed a marginally non-significant effect for reduction of depression between 7 and 15 days after treatment $(N=41, K=2, \mathrm{SMD}=$ -0.666 , CIs -1.374 to $\left.-0.042, p=0.065 ; I^{2}=13 \%\right)$ (Grob et al. 2011; Ross et al. 2016) (Fig. 3 and table S2). We can note that the medium-term clinical effects of classic psychedelics on depressive symptoms were mainly driven by data from the ayahuasca study.

The assessment of the longer-term (16 to 60 days) effect of psychedelics on the reduction of depressive symptoms revealed a highly significant effect with a moderate to large effect size $(N=$ $92, K=3, \mathrm{SMD}=-0.792$, CIs -1.222 to $-0.362, p<0.001$; $I^{2}=4.8 \%$ ) (Gasser et al. 2014; Griffiths et al. 2006; Ross et al. 2016) (Fig. 3 and table S2). The sub-analysis of psilocybin trials only also showed a large clinical effect in the reduction of depressive symptoms in patients with mood disorders, with low heterogeneity between studies $(N=80, K=2, \mathrm{SMD}=-0.826$, CIs -1.285 to $-0.367, p<0.001 ; I^{2}=5.5 \%$ ) (Griffiths et al. 2016; Ross et al. 2016) (Fig. 3 and table S2).

\section{Safety and tolerability}

From the 12 studies included, 3 did not detail data pertaining to safety or tolerability of the psychedelic used (Kometer et al. 2012; Kraehenmann et al. 2015; Wittmann et al. 2007). In 


\section{Effects of Psychedelics on Depressive Symptoms}

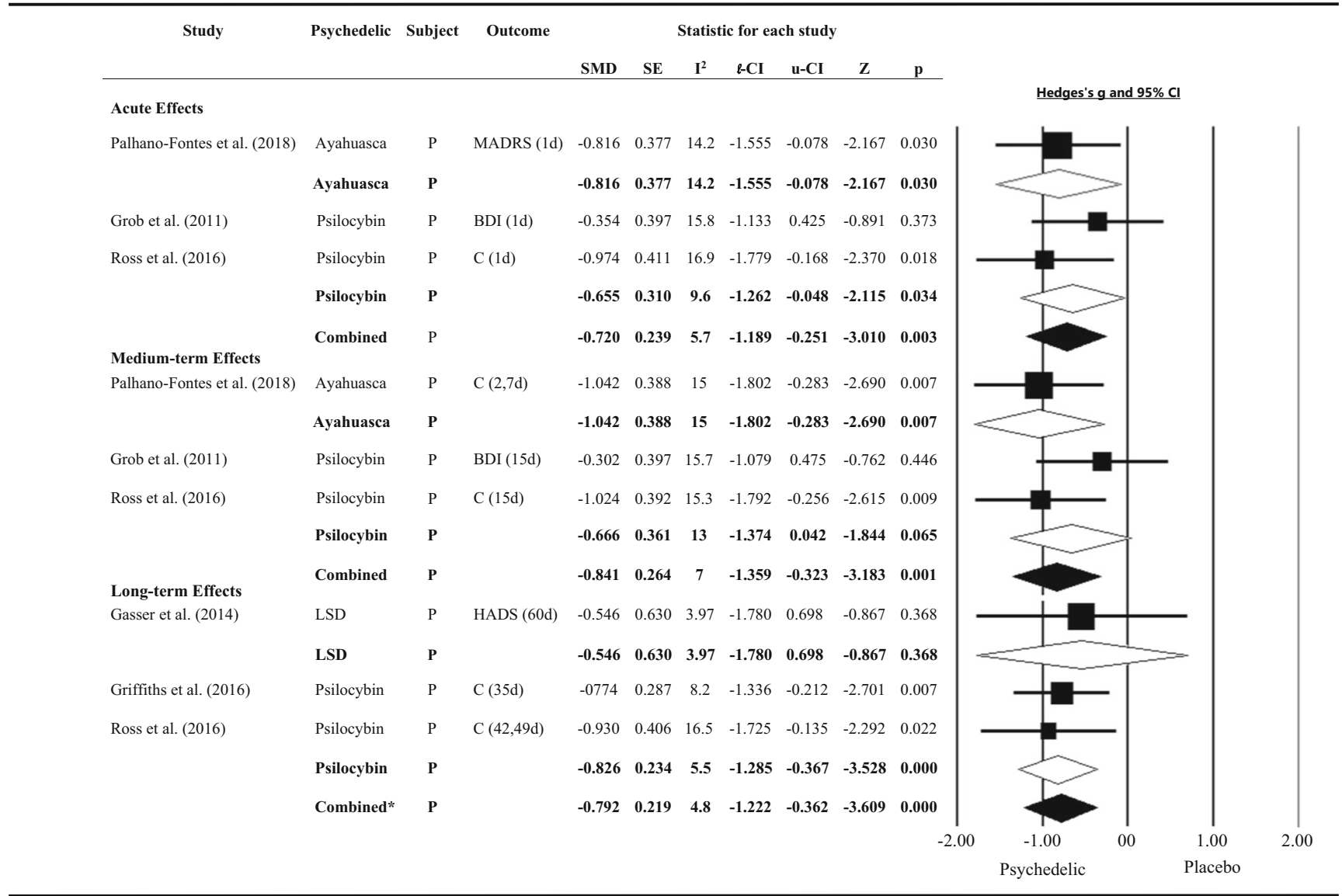

Fig. 3 Effect size (SMD) of acute, medium-term, and long-term clinical effects of classic serotonergic psychedelics vs placebo treatments on depressive symptoms of patients with mood disorders $(\mathrm{P})$, shown as Hedges' $g$ with $95 \%$ confidence interval. A negative Hedges' g indicates favor of psychedelics. Squares represent study effect sizes; open diamonds represent effect sizes of sub-group analyses by drug (psilocybin, lysergic acid diethylamide [LSD], and ayahuasca); closed diamonds represent overall effect sizes of each time-point (acute, medium term, and long term). The sizes of squares and diamonds are proportional to the

general, the other clinical trials reported that classic serotonergic psychedelics were well-tolerated. Acute psychological side-effects induced by psychedelics in the included studies were mainly mild anxiety episodes, tearing/crying, nausea, vomit, headache, and slight sympathomimetic effect, such as increase in blood pressure, heart rate, and pupil size, and rare episodes of paranoia was related. No study participants were noted as requiring pharmacological intervention to address these side-effects. Long-term studies did not indicate any persistent anxiety, suicidal crisis, or psychotic state.

\section{Publication bias}

With concern of publication bias, the fail-safe $N$ of this metaanalysis is $114(N=12, Z=-6.339, p<0.001)$. There would need to be 9.5 missing studies for every observed study for the
SMD. Combined: pooled ayahuasca and psilocybin. Combined*: pooled LSD and psilocybin. d: day and h: hours. C: The score of the following instruments were grouped and the mean of SMD was used in analysis, for Ross et al. (2016) and Griffiths et al. (2016), Beck Depression Inventory (BDI) and Hospital Anxiety and Depression Scale (HADS); PalhanoFontes et al. (2019), Hamilton Depression Rating Scale and Montgomery-Åsberg Depression Rating Scale (MADRS). SE, standard error; 1-IC, low confidence interval; u-CI, up confidence interval; $I^{2}$, heterogeneity across studies $(\%) ; Z, z$ value; $\mathrm{p}, p$ value

effect to be nullified. Egger's regression test of the intercept also did not report publication bias ( $\mathrm{B} 0=-0.191, \mathrm{IC}=-2.541$ to 2.158, $t=0.181, \mathrm{df}=10,1$-tailed $p=0.429$ ). For the funnel plot of publication bias, see supplementary material figure S1.

\section{Discussion}

This meta-analysis combined and evaluated data from 12 double-blind RCTs investigating the efficacy of classic serotonergic psychedelics on mood state and depressive symptoms, between $3 \mathrm{~h}$ and 60 days after administration, in patients with mood disorders, and healthy volunteers, separately. We observed a significant moderate effect size for reduction of acute negative mood outcomes in healthy volunteers, compared to placebo, as well as significant moderate effects sizes 
for acute and long-term reductions of negative mood state in patients with mood disorders. For depressive symptoms, a significant large effect size was detected from a mediumterm assessment, and a moderate effect size for both acute and long-term outcomes was observed for patients, compared to placebo.

Trials that assessed mood state response to psychedelics were in general conducted in healthy volunteers and mainly assessed acute outcomes. In this context, secondary analysis by psychedelic drug revealed moderate effect sizes for both psilocybin and LSD, with a slightly larger effect size for LSD. A significant moderate effect size in studies assessing the acute reduction of negative mood also was observed to patients in psilocybin trials. An analysis of longer-term data (16-60 days after treatment) indicated that psilocybin maintains its response on negative mood reduction of patients, with a moderate effect size compared to placebo. In this meta-analysis, it was not possible to undertake a meta-analysis for medium-term mood changes due to insufficient clinical trials.

It is important study the effects of classic psychedelics in both healthy volunteers and those with diagnosed mood disorders because as their neurobiology is distinct, and the psychobiological responses to drugs can be different between these populations (Galvão et al. 2018). It is essential to understand if any mood-elevating effects are evident in healthy participants, and to be able to compare this with the response of those with clinical depression. For note, it is usual that clinical trials select only one of these groups, with few studies assessing parallels groups of patients and healthy controls (de Almeida et al. 2019; Galvão et al. 2018; Galvão-Coelho et al. 2020). This meta-analysis provides a data analysis of negative mood in both healthy participants and patients with mood disorders, to differentially assess both populations.

The larger effect size of LSD in acute reductions of negative mood, in comparison to psilocybin, may be due to differing pharmacokinetic profiles (Libânio Osorio Marta 2019). While the onset of psychedelic effects is typically faster with psilocybin, around $30 \mathrm{~min}$ vs $1 \mathrm{~h}$ for LSD, the total duration of psilocybin acute effects are substantially shorter, at around $3.5 \mathrm{~h}$, compared with 8 to $12 \mathrm{~h}$ for LSD, depending on dose (Araujo et al. 2015; Dolder et al. 2017). However, pharmacokinetic data in this area remains limited. Besides classic serotonergic psychedelics, few double-blinded, placebo-controlled clinical trials have aimed to analyze acute mood changes in response to substances with psychedelic action (Krystal et al. 2006; Micallef et al. 2003). Furthermore, positive results for ketamine treatment in reduction of negative mood are for example observed 1 day after its administration, when compared with midazolam treatment (Grunebaum et al. 2018).

Psychedelics, specifically psilocybin and ayahuasca, demonstrated a moderate effect size in the acute reduction of depressive symptoms compared to placebo. The fast onset of therapeutic response is a key characteristic of new potential "fast- acting antidepressants," which aside from classic psychedelics also may include ketamine (Corriger and Pickering 2019; Ly et al. 2018). Animal models reveal that the biological therapeutic actions of antidepressants may in part be mediated via increased neuroplasticity through the expression of brain-derived neurotropic factor (BDNF) and its tyrosine kinase receptors type $\mathrm{B}$ in the prefrontal cortex and hippocampus (Mannari et al. 2008; Pilar-Cuéllar et al. 2012). Therefore, the delay in the therapeutic onset may potentially correlate with the time required for the elevation of the BDNF (Jesulola et al. 2018). While fast-acting antidepressants also induce neuroplasticity by BDNF increases, both in vitro and in vivo, this occurs through a pathway different and faster than that of antidepressants, involving the mammalian target of rapamycin (Ly et al. 2018). Moreover, it has been suggested that substances with psychedelic effect are able to reframe negative memories, which is in contrast to standard antidepressant pharmacotherapy in which new information is processed with a positive bias (Harmer et al. 2017; Kometer et al. 2012).

The present meta-analysis also revealed a large effect size of psychedelics (psilocybin, LSD, and ayahuasca) compared to placebo, in the reduction of depressive symptoms in mediumterm investigations, that is, between 2 and 15 days after treatment, which was evident from the ayahuasca study. A moderate effect size was seen for other psychedelics (LSD and psilocybin) in the longer-term analysis (between 16 and 60 days after interventions). Though it should be noted that this was due to the assessment time-points employed, and not necessarily to do with the length of ongoing antidepressant effect, another agent with a shorter alacrity of response than standard antidepressants, ketamine, suggests a similar temporal effects profile, with the strongest responses occurring between 1 and 2 weeks posttreatment (Corriger and Pickering 2019; Sanacora et al. 2017). Furthermore, a recent meta-analysis showed stronger effect sizes of classic psychedelics in reduction of depressive symptoms on days 7 and 21 after treatment comparing with baseline scores (Romeo et al. 2020).

Sub-analysis of trials using psilocybin with patients with a mood disorder and life-threatening disease identified moderate acute and large long-term effects of this substance in the reduction of depressive symptoms, when compared to placebo. These results are highly encouraging of further research with this group, as a recent meta-analysis of the use of antidepressants for cancer patients reported no indication of effects superior to placebo (Ostuzzi et al. 2018). The use of psychedelics in this population may extend beyond addressing affective symptoms, having a potentially specialized role in assisting with existential psychological distress involving mortality. However, it is important to highlight that mood disorders in these patients are often a comorbidity of the lifethreatening disease, and the depressive symptoms can be expressed in different ways for instance from the depressive patients where the depression is the main pathology. 
Although anxiety symptoms are often present in mood disorders, from 12 selected studies in systematic review, only 6 measured anxiety, and due the heterogeneity of these studies, it was not possible to conduct a meta-analysis with them (LSD, Gasser et al. 2014; Psylocibin; Grob et al. 2011; Kometer et al. 2012; Kraehenmann et al. 2015; Ross et al. 2016; Griffiths et al. 2016). However, it is important to highlight the importance of conducting this analysis when the data becomes available.

An additionally important point in this context is the use of "psychotherapy-assisted" applications of psychedelics. This approach may not only be safer (and more ethical); it may also provide a potentially stronger therapeutic effect. The psychedelic-assisted therapy, analyzed by studies that used MDMA and classic psychedelics, showed stronger clinical improvement of different mood and anxiety disorder than placebo (Luoma et al. 2020). This would however in the future be advised to be assessed via controlled research comparing psychedelic interventions alone and in combination with psychological assistance to determine if any additive or synergistic effect was evident. Moreover, such comparison would determine whether either intervention provides better management of any psychological distress which may emerge during consumption of the psychedelic.

It is also important to note that despite the low number of studies included in meta-analysis, low statistical heterogeneity was observed across clinical trials and no publication bias was detected. Moreover, in general, the included clinical trials indicated that classic serotonergic psychedelics are well-tolerated, although more reporting precision on adverse effects and longer safety follow-ups are recommended in future studies. Acute psychological and psychological side-effects were mainly mild anxiety episodes and sympathomimetic effects, such as increases in blood pressure, heart rate, and pupil size, which were short-lived and did not require pharmacological intervention.

There are several critical challenges recognized in conducting robust double-blind studies involving psychedelics. As revealed in our assessment of the methodological quality of the studies reviewed, a significant issue was evident regarding the presence of adequate blinding. In particular, some studies did not report any details regarding the placebo used, while others used a placebo which may or may not have active effects. To address the issue of sufficient blinding, some trials have used "active" placebos, such as low doses of psychedelics or methylphenidate and niacin, which can induce mild physiologic and cognitive changes. This is a wellneeded methodological advancement; however, some studies still find issues in blinding process even after this approach. Therefore, we must consider that unblinding is, at least in part, responsible for the magnitude of the effect size provided in this meta-analysis. Moreover, the expectancy of participants and evaluators about the treatment can also modulate the results. Despite 3 studies detailing strategies to deal with this potential expectation, none included expectancy measures as a covariate in statistical analysis of clinical response, and this should be considered in future studies.

Another issue of concern is the conducting of trials with multiple sessions of psychedelics or cross-over designs. Most included studies in this review used a cross-over study design, introducing possible limitations related to potential carry-over effects, as this raises the chance of the first session experience increasing the expectation bias of next session (or resulting in a carry-over effect if the active intervention is firstly used). Moreover, how the data analysis is communicated in crossover studies should be better considered by the researchers. For instance, separate analyses of the first and second crossover treatment administered, rather than having these both results analyzed together, are potentially a clearer method. Additionally, some included clinical trials did not provide adequate detail about the randomization strategy used and how participant withdrawals were handled in the analysis, making risk of bias assessment for these domains difficult. Further studies in this area are recommended to ensure adequate reporting of randomization procedures in line with international reporting guidelines (Higgins and Green 2011). Other limitations should also be taken in account in this meta-analysis: the small sample sizes of the included studies, the high heterogeneity in study design and population, multiple psychedelic doses, variety of outcome scales used, and different time-points assessed. For the last point, we acknowledge that analyzing the long-term effects may not entirely be methodologically sound due to the long duration between substance use and data collection. Therefore, future studies should consider these aspects with the aim of improving the quality of trials (Johnson et al. 2008).

In summation, methodological weaknesses aside, our meta-analysis provides encouraging evidence for the potential use of classic serotonergic psychedelics in the reduction of both negative mood state and depressive symptoms. While there are currently limited studies that have investigated some of these agents (in particular ayahuasca), the promising results of this review support the need for ongoing and more robust research in this emerging field to further explore the effect of psychedelics in adults with depression.

Supplementary Information The online version contains supplementary material available at https://doi.org/10.1007/s00213-020-05719-1.

Funding NLGC is supported by Coordenação de Aperfeiçoamento de Pessoal de Nível Superior - Brasil (Capes) (Finance code: 001/Research Fellowship 88887.466701/2019-00) and National Science and Technology Institute for Translational Medicine (INCT-TM Fapesp 2014/50891-1; CNPq 465458/2014-9). JS is supported by an NHMRC Clinical Research Fellowship (APP1125000). WM is supported by an Alfred Deakin Postdoctoral Research Fellow and a Multiple Sclerosis Research Australia early career fellowship. 


\section{Compliance with ethical standards}

Conflict of interest The authors declare that they have no conflict of interest.

Open Access This article is licensed under a Creative Commons Attribution 4.0 International License, which permits use, sharing, adaptation, distribution and reproduction in any medium or format, as long as you give appropriate credit to the original author(s) and the source, provide a link to the Creative Commons licence, and indicate if changes were made. The images or other third party material in this article are included in the article's Creative Commons licence, unless indicated otherwise in a credit line to the material. If material is not included in the article's Creative Commons licence and your intended use is not permitted by statutory regulation or exceeds the permitted use, you will need to obtain permission directly from the copyright holder. To view a copy of this licence, visit http://creativecommons.org/licenses/by/4.0/.

\section{References}

Akil H, Gordon J, Hen R, Javitch J, Mayberg H, McEwen B, Meaney MJ, Nestler EJ (2018) Treatment resistant depression: a multi-scale, systems biology approach. Neurosci Biobehav Rev 84:272-288. https://doi.org/10.1016/j.neubiorev.2017.08.019

Araujo AM, Carvalho F, Bastos Mde L, Guedes de Pinho P, Carvalho M (2015) The hallucinogenic world of tryptamines: an updated review. Arch Toxicol 89:1151-1173. https://doi.org/10.1007/s00204-015$1513-\mathrm{x}$

Ballenger J (2008) Safety, tolerability, and efficacy of psilocybin in 9 patients with obsessive-compulsive disorder. Yearbook of Psychiatry and Applied Mental Health:242-243

Baumeister D, Barnes G, Giaroli G, Tracy D (2014) Classical hallucinogens as antidepressants? A review of pharmacodynamics and putative clinical roles. Ther Adv Psychopharmacol 4:156-169. https:// doi.org/10.1177/2045125314527985

Berlin L, Guthrie T, Weider A, Goodell H, Wolff HG (1955) Studies in human cerebral function: the effects of mescaline and lysergic acid on cerebral processes pertinent to creative activity. J Nerv Ment Dis 122:487-491

Bershad AK, Schepers ST, Bremmer MP, Lee R, de Wit H (2019) Acute subjective and behavioral effects of microdoses of lysergic acid diethylamide in healthy human volunteers. Biol Psychiatry 86: 792-800. https://doi.org/10.1016/j.biopsych.2019.05.019

Blier P, de Montigny C (1994) Current advances and trends in the treatment of depression. Trends Pharmacol Sci 15:220-226. https://doi. org/10.1016/0165-6147(94)90315-8

Blum K, Futterman SL, Pascarosa P (1977) Peyote, a potential ethnopharmacologic agent for alcoholism and other drug dependencies: possible biochemical rationale. Clin Toxicol 11:459-472. https://doi.org/10.3109/15563657708988210

Bogenschutz MP, Johnson MW (2016) Classic hallucinogens in the treatment of addictions. Prog Neuro-Psychopharmacol Biol Psychiatry 64:250-258. https://doi.org/10.1016/j.pnpbp.2015.03.002

Bogenschutz MP, Ross S (2018) Therapeutic applications of classic hallucinogens. Curr Top Behav Neurosci 36:361-391. https://doi.org/ 10.1007/7854_2016_464

Bogenschutz MP, Forcehimes AA, Pommy JA, Wilcox CE, Barbosa PC, Strassman RJ (2015) Psilocybin-assisted treatment for alcohol dependence: a proof-of-concept study. J Psychopharmacol 29:289 299. https://doi.org/10.1177/0269881114565144

Carhart-Harris RL, Williams TM, Sessa B, Tyacke RJ, Rich AS, Feilding A, Nutt DJ (2011) The administration of psilocybin to healthy, hallucinogen-experienced volunteers in a mock-functional magnetic resonance imaging environment: a preliminary investigation of tolerability. J Psychopharmacol 25:1562-1567. https://doi.org/10. 1177/0269881110367445

Carhart-Harris RL, Bolstridge M, Rucker J, Day CMJ, Erritzoe D, Kaelen M, Bloomfield M, Rickard JA, Forbes B, Feilding A, Taylor D, Pilling S, Curran VH, Nutt DJ (2016a) Psilocybin with psychological support for treatment-resistant depression: an open-label feasibility study. Lancet Psychiatry 3:619-627. https://doi.org/10.1016/ S2215-0366(16)30065-7

Carhart-Harris RL, Kaelen M, Bolstridge M, Williams TM, Williams LT, Underwood R, Feilding A, Nutt DJ (2016b) The paradoxical psychological effects of lysergic acid diethylamide (LSD). Psychol Med 46:1379-1390. https://doi.org/10.1017/s0033291715002901

Carhart-Harris RL, Roseman L, Bolstridge M, Demetriou L, Pannekoek JN, Wall MB, Tanner M, Kaelen M, McGonigle J, Murphy K, Leech R, Curran HV, Nutt DJ (2017) Psilocybin for treatmentresistant depression: fMRI-measured brain mechanisms. Sci Rep 7:13187. https://doi.org/10.1038/s41598-017-13282-7

Carhart-Harris RL, Bolstridge M, Day CMJ, Rucker J, Watts R, Erritzoe DE, Kaelen M, Giribaldi B, Bloomfield M, Pilling S, Rickard JA, Forbes B, Feilding A, Taylor D, Curran HV, Nutt DJ (2018) Psilocybin with psychological support for treatment-resistant depression: six-month follow-up. Psychopharmacology 235:399408. https://doi.org/10.1007/s00213-017-4771-x

Carvalho AF, Sharma MS, Brunoni AR, Vieta E, Fava GA (2016) The safety, tolerability and risks associated with the use of newer generation antidepressant drugs: a critical review of the literature. Psychother Psychosom 85:270-288. https://doi.org/10.1159/ 000447034

Chi T, Gold JA (2020) A review of emerging therapeutic potential of psychedelic drugs in the treatment of psychiatric illnesses. J Neurol Sci 411:116715. https://doi.org/10.1016/j.jns.2020.116715

Cipriani A, Furukawa TA, Salanti G, Chaimani A, Atkinson LZ, Ogawa Y, Leucht S, Ruhe HG, Turner EH, Higgins JPT, Egger M, Takeshima N, Hayasaka Y, Imai H, Shinohara K, Tajika A, Ioannidis JPA, Geddes JR (2018) Comparative efficacy and acceptability of 21 antidepressant drugs for the acute treatment of adults with major depressive disorder: a systematic review and network meta-analysis. Lancet 391:1357-1366. https://doi.org/10.1016/ S0140-6736(17)32802-7

Conway CR, George MS, Sackeim HA (2017) Toward an evidencebased, operational definition of treatment-resistant depression: when enough is enough. JAMA Psychiatry 74:9-10. https://doi.org/10. 1001/jamapsychiatry.2016.2586

Corriger A, Pickering G (2019) Ketamine and depression: a narrative review. Drug Des Devel Ther 13:3051-3067. https://doi.org/10. 2147/dddt.S221437

Daumann J, Heekeren K, Neukirch A, Thiel CM, Moller-Hartmann W, Gouzoulis-Mayfrank E (2008) Pharmacological modulation of the neural basis underlying inhibition of return (IOR) in the human 5HT2A agonist and NMDA antagonist model of psychosis. Psychopharmacology 200:573-583. https://doi.org/10.1007/ s00213-008-1237-1

de Almeida RN, Galvão ACM, da Silva FS, Silva E, Palhano-Fontes F, Maia-de-Oliveira JP, de Araujo LB, Lobao-Soares B, GalvãoCoelho NL (2019) Modulation of serum brain-derived neurotrophic factor by a single dose of ayahuasca: observation from a randomized controlled trial. Front Psychol 10:1234. https://doi.org/10.3389/ fpsyg.2019.01234

Dolder PC, Schmid Y, Muller F, Borgwardt S, Liechti ME (2016) LSD acutely impairs fear recognition and enhances emotional empathy and sociality. Neuropsychopharmacology 41:2638-2646. https:// doi.org/10.1038/npp.2016.82

Dolder PC, Schmid Y, Steuer AE, Kraemer T, Rentsch KM, Hammann F, Liechti ME (2017) Pharmacokinetics and pharmacodynamics of 
lysergic acid diethylamide in healthy subjects. Clin Pharmacokinet 56:1219-1230. https://doi.org/10.1007/s40262-017-0513-9

Dos Santos RG, Valle M, Bouso JC, Nomdedeu JF, Rodriguez-Espinosa J, McIlhenny EH, Barker SA, Barbanoj MJ, Riba J (2011) Autonomic, neuroendocrine, and immunological effects of ayahuasca: a comparative study with d-amphetamine. J Clin Psychopharmacol 31:717-726. https://doi.org/10.1097/JCP. 0b013e31823607f6

Dos Santos RG, Bouso JC, Alcazar-Corcoles MA, Hallak JEC (2018) Efficacy, tolerability, and safety of serotonergic psychedelics for the management of mood, anxiety, and substance-use disorders: a systematic review of systematic reviews. Expert Rev Clin Pharmacol 11:889-902. https://doi.org/10.1080/17512433.2018.1511424

Fuentes JJ, Fonseca F, Elices M, Farre M, Torrens M (2019) Therapeutic use of LSD in psychiatry: a systematic review of randomizedcontrolled clinical trials. Front Psychiatry 10:943. https://doi.org/ $10.3389 /$ fpsyt.2019.00943

Galvão ACM, de Almeida RN, Silva E, Freire FAM, Palhano-Fontes F, Onias H, Arcoverde E, Maia-de-Oliveira JP, de Araujo DB, LobaoSoares B, Galvão-Coelho NL (2018) Cortisol modulation by ayahuasca in patients with treatment resistant depression and healthy controls. Front Psychiatry 9:185. https://doi.org/10.3389/fpsyt. 2018.00185

Galvão-Coelho NL, Galvão ACM, de Almeida RN, Palhano-Fontes F, Braga IC, Lobão-Soares B et al (2020) Changes in inflammatory biomarkers are related to the antidepressant effects of ayahuasca. J Psychopharmacol 34:1125-1133. https://doi.org/10.1177/ 0269881120936486

Gasser P, Holstein D, Michel Y, Doblin R, Yazar-Klosinski B, Passie T, Brenneisen R (2014) Safety and efficacy of lysergic acid diethylamide-assisted psychotherapy for anxiety associated with life-threatening diseases. J Nerv Ment Dis 202:513-520. https:// doi.org/10.1097/nmd.0000000000000113

Gasser P, Kirchner K, Passie T (2015) LSD-assisted psychotherapy for anxiety associated with a life-threatening disease: a qualitative study of acute and sustained subjective effects. J Psychopharmacol 29:5768. https://doi.org/10.1177/0269881114555249

Gouzoulis-Mayfrank E, Hermle L, Thelen B, Sass H (1998) History, rationale and potential of human experimental hallucinogenic drug research in psychiatry. Pharmacopsychiatry 31:63-68. https://doi. org/10.1055/s-2007-979348

Gouzoulis-Mayfrank E, Heekeren K, Neukirch A, Stoll M, Stock C, Obradovic M, Kovar KA (2005) Psychological effects of (S)-ketamine and N,N-dimethyltryptamine (DMT): a double-blind, crossover study in healthy volunteers. Pharmacopsychiatry 38:301-311. https://doi.org/10.1055/s-2005-916185

Griffiths RR, Richards WA, McCann U, Jesse R (2006) Psilocybin can occasion mystical-type experiences having substantial and sustained personal meaning and spiritual significance. Psychopharmacology 187:268-283. https://doi.org/10.1007/s00213-006-0457-5

Griffiths R, Richards W, Johnson M, McCann U, Jesse R (2008) Mystical-type experiences occasioned by psilocybin mediate the attribution of personal meaning and spiritual significance 14 months later. J Psychopharmacol 22:621-632. https://doi.org/10.1177/ 0269881108094300

Griffiths RR, Johnson MW, Carducci MA, Umbricht A, Richards WA, Richards BD, Cosimano MP, Klinedinst MA (2016) Psilocybin produces substantial and sustained decreases in depression and anxiety in patients with life-threatening cancer: a randomized double-blind trial. J Psychopharmacol 30:1181-1197. https://doi.org/10.1177/ 0269881116675513

Grob CS, Danforth AL, Chopra GS, Hagerty M, McKay CR, Halberstadt AL, Greer GR (2011) Pilot study of psilocybin treatment for anxiety in patients with advanced-stage cancer. Arch Gen Psychiatry 68:7178. https://doi.org/10.1001/archgenpsychiatry.2010.116
Grunebaum MF, Galfalvy HC, Choo TH, Keilp JG, Moitra VK, Parris MS, Marver JE, Burke AK, Milak MS, Sublette ME, Oquendo MA, Mann JJ (2018) Ketamine for rapid reduction of suicidal thoughts in major depression: a midazolam-controlled randomized clinical trial. Am J Psychiatry 175:327-335. https://doi.org/10.1176/appi.ajp. 2017.17060647

Halberstadt AL, Geyer MA (2011) Multiple receptors contribute to the behavioral effects of indoleamine hallucinogens. Neuropharmacology 61:364-381. https://doi.org/10.1016/j. neuropharm.2011.01.017

Harmer CJ, Duman RS, Cowen PJ (2017) How do antidepressants work? New perspectives for refining future treatment approaches. Lancet Psychiatry 4:409-418. https://doi.org/10.1016/s2215-0366(17) 30015-9

Hasler F, Grimberg U, Benz MA, Huber T, Vollenweider FX (2004) Acute psychological and physiological effects of psilocybin in healthy humans: a double-blind, placebo-controlled dose-effect study. Psychopharmacology 172:145-156. https://doi.org/10.1007/ s00213-003-1640-6

Heffter A (1898) Ueber Pellote. Arch Exp Pathol Pharmakol 40:385-429. https://doi.org/10.1007/BF01825267

Hengartner MP, Plöderl M (2018) Statistically significant antidepressantplacebo differences on subjective symptom-rating scales do not prove that the drugs work: effect size and method bias matter! Front Psychiatry 9:517. https://doi.org/10.3389/fpsyt.2018.00517

Higgins J, Green S (2011) Cochrane Handbook for Systematic Reviews of Interventions Version 5.1.0 [updated March 2011]. The Cochrane Collaboration. www.handbook.cochrane.org

Hofmann A (1979) How LSD originated. J Psychedelic Drugs 11:53-60. https://doi.org/10.1080/02791072.1979.10472092

Jadad AR, Moore RA, Carroll D, Jenkinson C, Reynolds DJ, Gavaghan DJ, McQuay HJ (1996) Assessing the quality of reports of randomized clinical trials: is blinding necessary? Control Clin Trials 17:112. https://doi.org/10.1016/0197-2456(95)00134-4

Jesulola E, Micalos P, Baguley IJ (2018) Understanding the pathophysiology of depression: from monoamines to the neurogenesis hypothesis model - are we there yet? Behav Brain Res 341:79-90. https:// doi.org/10.1016/j.bbr.2017.12.025

Johansen PO, Krebs TS (2015) Psychedelics not linked to mental health problems or suicidal behavior: a population study. J Psychopharmacol 29:270-279. https://doi.org/10.1177/ 0269881114568039

Johnson M, Richards W, Griffiths R (2008) Human hallucinogen research: guidelines for safety. J Psychopharmacol 22:603-620. https://doi.org/10.1177/0269881108093587

Johnson MW, Garcia-Romeu A, Cosimano MP, Griffiths RR (2014) Pilot study of the 5-HT2AR agonist psilocybin in the treatment of tobacco addiction. J Psychopharmacol 28:983-992. https://doi.org/ 10.1177/0269881114548296

Johnson MW, Hendricks PS, Barrett FS, Griffiths RR (2019) Classic psychedelics: an integrative review of epidemiology, therapeutics, mystical experience, and brain network function. Pharmacol Ther 197:83-102. https://doi.org/10.1016/j.pharmthera.2018.11.010

Kaelen M, Giribaldi B, Raine J, Evans L, Timmerman C, Rodriguez N, Roseman L, Feilding A, Nutt D, Carhart-Harris R (2018) The hidden therapist: evidence for a central role of music in psychedelic therapy. Psychopharmacology 235:505-519. https://doi.org/10.1007/ s00213-017-4820-5

Kirsch I (2014) Antidepressants and the placebo effect. Z Psychol 222: 128-134. https://doi.org/10.1027/2151-2604/a000176

Kometer M, Schmidt A, Bachmann R, Studerus E, Seifritz E, Vollenweider FX (2012) Psilocybin biases facial recognition, goaldirected behavior, and mood state toward positive relative to negative emotions through different serotonergic subreceptors. Biol Psychiatry 72:898-906. https://doi.org/10.1016/j.biopsych.2012. 04.005 
Kraehenmann R, Preller KH, Scheidegger M, Pokorny T, Bosch OG, Seifritz E, Vollenweider FX (2015) Psilocybin-induced decrease in amygdala reactivity correlates with enhanced positive mood in healthy volunteers. Biol Psychiatry 78:572-581. https://doi.org/10. 1016/j.biopsych.2014.04.010

Krebs TS, Johansen PO (2012) Lysergic acid diethylamide (LSD) for alcoholism: meta-analysis of randomized controlled trials. J Psychopharmacol 26:994-1002. https://doi.org/10.1177/ 0269881112439253

Krebs TS, Johansen PO (2013) Psychedelics and mental health: a population study. PLoS One 8:e63972. https://doi.org/10.1371/journal. pone. 0063972

Krystal JH, Madonick S, Perry E, Gueorguieva R, Brush L, Wray Y, Belger A, D'Souza DC (2006) Potentiation of low dose ketamine effects by naltrexone: potential implications for the pharmacotherapy of alcoholism. Neuropsychopharmacology 31:1793-1800. https://doi.org/10.1038/sj.npp.1300994

Libânio Osorio Marta RF (2019) Metabolism of lysergic acid diethylamide (LSD): an update. Drug Metab Rev 51:378-387. https://doi.org/10.1080/03602532.2019.1638931

Luoma JB, Chwyl C, Bathje GJ, Davis AK, Lancelotta R (2020) A metaanalysis of placebo-controlled trials of psychedelic-assisted therapy. J Psychoactive Drugs:1-11. https://doi.org/10.1080/02791072. 2020.1769878

Ly C, Greb AC, Cameron LP, Wong JM, Barragan EV, Wilson PC, Burbach KF, Soltanzadeh Zarandi S, Sood A, Paddy MR, Duim WC, Dennis MY, McAllister AK, Ori-McKenney KM, Gray JA, Olson DE (2018) Psychedelics promote structural and functional neural plasticity. Cell Rep 23:3170-3182. https://doi.org/10.1016/ j.celrep.2018.05.022

Lyons T, Carhart-Harris RL (2018a) Increased nature relatedness and decreased authoritarian political views after psilocybin for treatment-resistant depression. J Psychopharmacol 32:811-819. https://doi.org/10.1177/0269881117748902

Lyons T, Carhart-Harris RL (2018b) More realistic forecasting of future life events after psilocybin for treatment-resistant depression. Front Psychol 9:1721. https://doi.org/10.3389/fpsyg.2018.01721

Mannari C, Origlia N, Scatena A, Del Debbio A, Catena M, Dell'agnello G, Barraco A, Giovannini L, Dell'osso L, Domenici L, Piccinni A (2008) BDNF level in the rat prefrontal cortex increases following chronic but not acute treatment with duloxetine, a dual acting inhibitor of noradrenaline and serotonin re-uptake. Cell Mol Neurobiol 28:457-468. https://doi.org/10.1007/s10571-007-9254-x

McKenna DJ (2004) Clinical investigations of the therapeutic potential of ayahuasca: rationale and regulatory challenges. Pharmacol Ther 102:111-129. https://doi.org/10.1016/j.pharmthera.2004.03.002

Micallef J, Tardieu S, Gentile S, Fakra E, Jouve E, Sambuc R, Blin O (2003) Effects of a subanaesthetic dose of ketamine on emotional and behavioral state in healthy subjects. Neurophysiol Clin 33:138147. https://doi.org/10.1016/s0987-7053(03)00028-5

Moher D, Liberati A, Tetzlaff J, Altman DG (2009) Preferred reporting items for systematic reviews and meta-analyses: the PRISMA statement. PLoS Med 6:e1000097. https://doi.org/10.1371/journal. pmed. 1000097

Moreno FA, Wiegand CB, Taitano EK, Delgado PL (2006) Safety, tolerability, and efficacy of psilocybin in 9 patients with obsessivecompulsive disorder. J Clin Psychiatry 67:1735-1740. https://doi. org/10.4088/jcp.v67n1110

Munkholm K, Paludan-Müller AS, Boesen K (2019) Considering the methodological limitations in the evidence base of antidepressants for depression: a reanalysis of a network meta-analysis. BMJ Open 9:e024886. https://doi.org/10.1136/bmjopen-2018-024886

Muttoni S, Ardissino M, John C (2019) Classical psychedelics for the treatment of depression and anxiety: a systematic review. J Affect Disord 258:11-24. https://doi.org/10.1016/j.jad.2019.07.076
Osorio Fde L, Sanches RF, Macedo LR, Santos RG, Maia-de-Oliveira JP, Wichert-Ana L, Araujo DB, Riba J, Crippa JA, Hallak JE (2015) Antidepressant effects of a single dose of ayahuasca in patients with recurrent depression: a preliminary report. Braz J Psychiatry 37:1320. https://doi.org/10.1590/1516-4446-2014-1496

Ostuzzi G, Matcham F, Dauchy S, Barbui C, Hotopf M (2018) Antidepressants for the treatment of depression in people with cancer. Cochrane Database Syst Rev 4:Cd011006. https://doi.org/10. 1002/14651858.CD011006.pub3

Pahnke WN, Kurland AA, Unger S, Savage C, Wolf S, Goodman LE (1970) Psychedelic therapy (utilizing LSD) with cancer patients. J Psychedelic Drugs 3:63-75. https://doi.org/10.1080/02791072. 1970.10471363

Palhano-Fontes F, Alchieri J, Maia-de-Oliveira J, Oliveira M, Soares B, Hallak J, Galvão-Coelho N, de Araujo D, Palhano-Fontes F, Oliveira J, Soares B, Hallak J, Galvão-Coelho N, Labate B, Cavnar C (2014) The therapeutic potentials of ayahuasca in the treatment of depression. In: CCe LB (ed) The therapeutic use of Ayahuasca. Springer, Berlin. https://doi.org/10.1007/978-3-64240426-9 2

Palhano-Fontes F, Barreto D, Onias H, Andrade KC, Novaes MM, Pessoa JA, Mota-Rolim SA, Osorio FL, Sanches R, Dos Santos RG, Tofoli LF, de Oliveira SG, Yonamine M, Riba J, Santos FR, Silva-Junior AA, Alchieri JC, Galvão-Coelho NL, Lobao-Soares B, Hallak JEC, Arcoverde E, Maia-de-Oliveira JP, Araujo DB (2019) Rapid antidepressant effects of the psychedelic ayahuasca in treatment-resistant depression: a randomized placebo-controlled trial. Psychol Med 49:655-663. https://doi.org/10.1017/ s0033291718001356

Pathways C (2018) COMPASS Pathways receives FDA Breakthrough Therapy designation for psilocybin therapy for treatment-resistant depression. https://compasspathways.com/compass-pathwaysreceives-fda-breakthrough-therapy-designation-for-psilocybintherapy-for-treatment-resistant-depression/. Accessed 29 April 2020

Pilar-Cuéllar F, Vidal R, Pazos A (2012) Subchronic treatment with fluoxetine and ketanserin increases hippocampal brain-derived neurotrophic factor, $\beta$-catenin and antidepressant-like effects. Br J Pharmacol 165:1046-1057. https://doi.org/10.1111/j.1476-5381. 2011.01516.x

Posternak MA, Zimmerman M (2005) Is there a delay in the antidepressant effect? A meta-analysis. J Clin Psychiatry 66:148-158. https:// doi.org/10.4088/jcp.v66n0201

Reiff CM, Richman EE, Nemeroff CB, Carpenter LL, Widge AS, Rodriguez CI, Kalin NH, McDonald WM (2020) Psychedelics and psychedelic-assisted Psychotherapy. Am J Psychiatry: appiajp201919010035. https://doi.org/10.1176/appi.ajp.2019. 19010035

Riba J, Rodriguez-Fornells A, Urbano G, Morte A, Antonijoan R, Montero M, Callaway J, Barbanoj M (2001) Subjective effects and tolerability of the south American psychoactive beverage ayahuasca in healthy volunteers. Psychopharmacology 154:85-95. https://doi.org/10.1007/s002130000606

Romeo B, Karila L, Martelli C, Benyamina A (2020) Efficacy of psychedelic treatments on depressive symptoms: a meta-analysis. J Psychopharmacol:0269881120919957. https://doi.org/10.1177/ 0269881120919957

Roseman L, Nutt DJ, Carhart-Harris RL (2017) Quality of acute psychedelic experience predicts therapeutic efficacy of psilocybin for treatment-resistant depression. Front Pharmacol 8:974. https://doi. org/10.3389/fphar.2017.00974

Ross S (2012) Serotonergic hallucinogens and emerging targets for addiction pharmacotherapies. Psychiatr Clin North Am 35:357-374. https://doi.org/10.1016/j.psc.2012.04.002

Ross S (2018) Therapeutic use of classic psychedelics to treat cancerrelated psychiatric distress. Int Rev Psychiatry 30:317-330. https:// doi.org/10.1080/09540261.2018.1482261 
Ross S, Bossis A, Guss J, Agin-Liebes G, Malone T, Cohen B, Mennenga SE, Belser A, Kalliontzi K, Babb J, Su Z, Corby P, Schmidt BL (2016) Rapid and sustained symptom reduction following psilocybin treatment for anxiety and depression in patients with lifethreatening cancer: a randomized controlled trial. J Psychopharmacol 30:1165-1180. https://doi.org/10.1177/ 0269881116675512

Rucker JJH, Iliff J, Nutt DJ (2018) Psychiatry \& the psychedelic drugs. Past, present \& future. Neuropharmacology 142:200-218. https:// doi.org/10.1016/j.neuropharm.2017.12.040

Sanacora G, Frye MA, McDonald W, Mathew SJ, Turner MS, Schatzberg AF, Summergrad P, Nemeroff CB (2017) A consensus statement on the use of ketamine in the treatment of mood disorders. JAMA Psychiatry 74:399-405. https://doi.org/10.1001/ jamapsychiatry.2017.0080

Sanches RF, de Lima OF, Dos Santos RG, Macedo LR, Maia-de-Oliveira JP, Wichert-Ana L, de Araujo DB, Riba J, Crippa JA, Hallak JE (2016) Antidepressant effects of a single dose of ayahuasca in patients with recurrent depression: a SPECT study. J Clin Psychopharmacol 36:77-81. https://doi.org/10.1097/jcp. 0000000000000436

Santos RG, Landeira-Fernandez J, Strassman RJ, Motta V, Cruz AP (2007) Effects of ayahuasca on psychometric measures of anxiety, panic-like and hopelessness in Santo Daime members. J Ethnopharmacol 112:507-513. https://doi.org/10.1016/j.jep.2007. 04.012

Schenberg EE (2018) Psychedelic-assisted psychotherapy: a paradigm shift in psychiatric research and development. Front Pharmacol 9: 733. https://doi.org/10.3389/fphar.2018.00733

Schmid Y, Liechti ME (2018) Long-lasting subjective effects of LSD in normal subjects. Psychopharmacology 235:535-545. https://doi. org/10.1007/s00213-017-4733-3
Schmid Y, Enzler F, Gasser P, Grouzmann E, Preller KH, Vollenweider FX, Brenneisen R, Muller F, Borgwardt S, Liechti ME (2015) Acute effects of lysergic acid diethylamide in healthy subjects. Biol Psychiatry 78:544-553. https://doi.org/10.1016/j.biopsych.2014. 11.015

Stroud JB, Freeman TP, Leech R, Hindocha C, Lawn W, Nutt DJ, Curran HV, Carhart-Harris RL (2018) Psilocybin with psychological support improves emotional face recognition in treatment-resistant depression. Psychopharmacology 235:459-466. https://doi.org/10. 1007/s00213-017-4754-y

Thase ME, Entsuah AR, Rudolph RL (2001) Remission rates during treatment with venlafaxine or selective serotonin reuptake inhibitors. Br J Psychiatry 178:234-241. https://doi.org/10.1192/bjp.178.3.234

Uthaug MV, van Oorsouw K, Kuypers KPC, van Boxtel M, Broers NJ, Mason NL, Toennes SW, Riba J, Ramaekers JG (2018) Sub-acute and long-term effects of ayahuasca on affect and cognitive thinking style and their association with ego dissolution. Psychopharmacology 235:2979-2989. https://doi.org/10.1007/ s00213-018-4988-3

Wittmann M, Carter O, Hasler F, Cahn BR, Grimberg U, Spring P, Hell D, Flohr H, Vollenweider FX (2007) Effects of psilocybin on time perception and temporal control of behaviour in humans. J Psychopharmacol 21:50-64. https://doi.org/10.1177/ 0269881106065859

Zeifman RJ, Palhano-Fontes F, Hallak J, Arcoverde E, Maia-Oliveira JP, Araujo DB (2019) The impact of ayahuasca on suicidality: results from a randomized controlled trial. Front Pharmacol 10:1325. https://doi.org/10.3389/fphar.2019.01325

Publisher's note Springer Nature remains neutral with regard to jurisdictional claims in published maps and institutional affiliations. 